\title{
PALPABILITY OF THE LIVER AND SPLEEN IN INFANTS AND CHILDREN
}

\author{
BY \\ BRIAN MCNICHOLL \\ From University College, Galway \\ (RECEIVED FOR PUBLICATION MAY 6, 1957)
}

The extent to which the liver and spleen project below the costal margin in infants and children does not seem to be generally known. This study was undertaken to define the normal range of palpable projection of the liver edge below the costal margin in different age groups and so help to resolve some of the conflicting views on the subject. The number of subjects in whom the spleen was palpable was also recorded.

\section{Material and Methods}

Three hundred and seventeen apparently healthy infants and children (166 males and 151 females) between birth and $16 \frac{1}{2}$ years were examined. A history of pathological jaundice or recent illness excluded any child. The subjects were found in nurseries, for newborn and premature babies, in orphanages and industrial schools.

The Liver. Measurements were made in the midclavicular line to the nearest half-centimetre with a short ruler, the zero mark of which was flush with the end of the ruler, this being firmly pressed against the costal margin. Measurements were made with the subject supine, the head being supported on a low pillow; they were made during the hour before meals, and in the case of some infants where abdominal relaxation was not otherwise obtained, during the first minutes of a feed. All measurements were, whenever possible, made in the end-expiratory position, that is during the momentary pause following quiet expiration. When the liver edge coincided, with or receded behind, the costal margin in the end-expiratory position, projection was recorded as zero. The liver edge was palpated with the left hand from the patient's left side; this method was rational, at least for those who find it easiest to palpate a pyloric or colonic tumour in the sub-hepatic region in this way.

The Spleen. It was found easiest to palpate the spleen with the right hand from the patient's right side.

No measurements of the projection of the spleen below the costal margin are given, the organ being recorded as palpable whether only palpated during quiet inspiration or otherwise.

Finding the liver or spleen in the first place is easiest when the fingers are kept stationary, movement of the diaphragm being relied on to push the viscus against the fingers.

\section{Results}

The Liver. The results are summarized in the table. The liver edge projected on average a little less than $2 \mathrm{~cm}$. in the mid-clavicular line in full-term infants in the newborn period (taken for convenience here to be the first 21 days); the range was 0.5 to $2.5 \mathrm{~cm}$. In premature infants, the average projection was slightly less, $1.6 \mathrm{~cm}$., range 1 to $2.5 \mathrm{~cm}$. From 21 days to 6 months, from 6 to 12 months and from 12 to 18 months, the average projection was $1 \cdot 5,1.8$ and $1.5 \mathrm{~cm}$. respectively, the range being 0 to $3.5 \mathrm{~cm}$. in each group. From $1 \frac{1}{2}$ to $5 \frac{1}{2}$ years the average projection was $1 \mathrm{~cm}$., range 0 to $3.5 \mathrm{~cm}$., from $5 \frac{1}{2}$ to $10 \frac{1}{2}$ years it was $1 \mathrm{~cm}$., range 0 to $3 \mathrm{~cm}$., and from $10 \frac{1}{2}$ to $16 \frac{1}{2}$ years it was $0.85 \mathrm{~cm}$., range 0 to $4 \mathrm{~cm}$.

As no marked difference between the sexes was apparent, the figures for males and females were added; there was a slight trend for both liver and spleen to project more in older boys. In 10 subjects $(3.4 \%$ of all examined) it was not found possible to palpate the liver edge accurately, usually due to inadequate relaxation, and these cases were discarded. The liver edge was found to be most nearly parallel with the right costal margin during the first year, during which time it was also most readily palpable in the right mid-axillary line and to the left of the midline. The edge of the left lobe of the liver can frequently be followed as far as the left mid-clavicular line in infancy, but beyond this age it becomes progressively more unusual to palpate it to the left of the subcostal notch. The amount of the anterior surface of the liver uncovered by the ribs is thus relatively greatest in the newborn period. The notches in the liver edge corresponding to the gall bladder and ligamentum teres were occasionally palpable, particularly with good relaxation of the abdominal wall in infants, the latter notch being defined with more difficulty due to the intervening 
rectus muscle. In the supine subject, the plane of the projecting anterior surface of the liver is approximately horizontal in most instances, that is to say, parallel to the contiguous anterior thoracic and abdominal walls. From about the fifth to the tenth year, in those subjects in whom the projection of the liver was greatest, it was frequently found that the anterior surface shelved downwards, the fingers needing to be pressed deeply into the abdomen to find the edge, which could on occasion be felt to ride up over the fingers on inspiration.

The Spleen. The spleen was palpated below the costal margin in $11.1 \%$ of the series; it was felt that attempts to measure the projection would be of little value. Projection tended to be less in the older age groups, when in fact it was frequently difficult to be sure whether there was any significant projection in the end-expiratory position, the spleen, however, being readily palpable during inspiration. The spleen was palpated in $13.5 \%$ of newborn infants, $12 \cdot 7 \%$ of those from 21 days to $1 \frac{1}{2}$ years, $7 \cdot 2 \%$ of those from $1 \frac{1}{2}$ to $10 \frac{1}{2}$ years and $16.6 \%$ of those from $10 \frac{1}{2}$ to $16 \frac{1}{2}$ years. This last figure of $16.6 \%$ in the $10 \frac{1}{2}$ to $16 \frac{1}{2}$ group may be due either to chance, or to some unrecognized infective or other factor, since the majority of those in this group in whom the spleen was palpated were boys from one institution, their liver projection being also in the higher ranges.

\section{Discussion}

Cruchet and Sérégé (1908) studied 160 subjects aged from birth to 18 years by palpation of the liver edge in axillary, nipple and mid lines. Their figures show the average projection of the liver edge in the nipple line at birth to be $4.7 \mathrm{~cm}$. (two cases only), falling abruptly to $0.4 \mathrm{~cm}$. during the second year (eight cases only), remaining at $2 \mathrm{~cm}$. from 5 years to 12 years and becoming impalpable at 14 years.

Nelson's Pediatrics (1954) states that 'in the newborn infant, the liver edge may be as much as $5 \mathrm{~cm}$. below the costal margin in the right M.C.L.' Abt's Pediatrics (1923) summarizes the findings of Cruchet and Sérégé (1908) thus :

'They found that the inferior margin of the right lobe rapidly approaches the right costal margin until the middle of the second year, when it again begins to descend until the middle of the second period of childhood. After this time a second period of ascent occurs, ending in adolescence with the right liver margin at the usual normal adult position.'

This statement has been repeated in almost identical words in Brenneman's Practice of Pediatrics and in Gaisford and Lightwood's Paediatrics for the Practitioner (1953).

Zamkin (1926) studied 2,100 apparently normal infants and children by palpation of the liver and spleen, the measurements being recorded in terms of the author's fingerbreadth and then transcribed into centimetres. $\mathrm{He}$ found the percentage of palpable livers to vary from $100 \%$ in the first year to $50 \%$ from 10 to 12 years, and of palpable spleens to vary from $43 \%$ in the first year to $10 \%$ from 10 to 12 years. The liver projected below the costal margin between 2.5 and $5.5 \mathrm{~cm}$. in the mid-clavicular line in $77 \%$ of subjects from 10 days to 1 year and in $74 \%$ of children from 2 to 4 years; these figures are in conflict with those of the present study and a projection of the liver below the costal margin in

TABLE

\begin{tabular}{|c|c|c|c|c|c|c|c|c|c|c|}
\hline \multicolumn{5}{|c|}{ Age } & $\begin{array}{l}\text { No. of } \\
\text { Subjects }\end{array}$ & \multicolumn{4}{|c|}{$\begin{array}{c}\text { Projection of Liver Edge below Costal Margin in } \\
\text { Mid-clavicular Line }\end{array}$} & \multirow[t]{2}{*}{$\begin{array}{l}\text { Palpable } \\
\text { Spleen }\end{array}$} \\
\hline \multirow[b]{2}{*}{$\begin{array}{l}\vec{T} \\
d \text { व } \\
21 \mathrm{~d} \\
6 \text { to } \\
12 \mathrm{t} \\
2 \mathrm{y} \\
3 \\
4 \\
5 \\
6 \\
7 \\
8 \\
9 \\
10 \\
11 \\
12 \\
13 \\
14 \\
15 \\
16\end{array}$} & & & & & & $\begin{array}{l}\text { Average in } \\
\mathrm{cm} .\end{array}$ & $\begin{array}{c}\text { Range in } \\
\mathrm{cm} .\end{array}$ & S.D. & $\begin{array}{l}\text { Zero } \\
\text { Projection }\end{array}$ & \\
\hline & 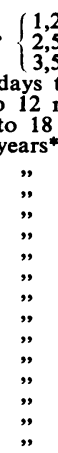 & $\begin{array}{l}250 \text { to } \\
500 \text { to } \\
500 \text { to } \\
\text { to } 6 \mathrm{~m} \\
\text { months } \\
\text { month } \\
\ldots \\
\ldots \\
\ldots \\
\ldots \\
\ldots \\
\ldots \\
\ldots \\
\ldots \\
\ldots \\
\ldots \\
\ldots \\
\ldots\end{array}$ & $\begin{array}{c}2,500 \\
3,500 \\
4,500 \\
\text { nonths } \\
\text { s } \ldots \\
\text { hs } \\
\ldots \\
\ldots \\
\ldots \\
\ldots \\
\ldots \\
\ldots \\
\ldots \\
\ldots \\
\ldots \\
\ldots \\
\ldots \\
\ldots\end{array}$ & $\begin{array}{r}\text { g... } \\
\text { g... } \\
\text {... } \\
\ldots \\
\ldots \\
\ldots \\
\ldots \\
\ldots \\
\ldots \\
\ldots \\
\ldots \\
\ldots \\
\ldots \\
\ldots \\
\ldots \\
\ldots \\
\ldots \\
\ldots\end{array}$ & $\begin{array}{l}11 \\
13 \\
13 \\
23 \\
18 \\
13 \\
22 \\
14 \\
25 \\
20 \\
17 \\
11 \\
15 \\
13 \\
16 \\
10 \\
11 \\
14 \\
17 \\
10 \\
11\end{array}$ & $\begin{array}{l}1 \cdot 59 \\
1.77 \\
2.04 \\
1.46 \\
1 \cdot 75 \\
1.46 \\
1 \cdot 13 \\
1.00 \\
0.64 \\
0.98 \\
0.76 \\
1 \cdot 14 \\
0.90 \\
1 \cdot 12 \\
1.00 \\
1.05 \\
1.18 \\
0.86 \\
0.86 \\
0.70 \\
0.68\end{array}$ & $\begin{array}{r}1 \text { to } 2 \cdot 5 \\
0.5 \text { to } 2 \cdot 5 \\
1 \cdot 5 \text { to } 2 \cdot 5 \\
0 \text { to } 3 \cdot 5 \\
0 \text { to } 3 \cdot 5 \\
0 \text { to } 3 \cdot 5 \\
0 \text { to } 3 \cdot 0 \\
0 \text { to } 3 \cdot 5 \\
0 \text { to } 2 \cdot 0 \\
0 \text { to } 3 \cdot 0 \\
0 \text { to } 3 \cdot 0 \\
0 \text { to } 2 \cdot 5 \\
0 \text { to } 2 \cdot 5 \\
0 \text { to } 2 \cdot 5 \\
0 \text { to } 3 \cdot 0 \\
0 \text { to } 3 \cdot 0 \\
0 \text { to } 4 \cdot 0 \\
0 \text { to } 3 \cdot 0 \\
0 \text { to } 2 \cdot 0 \\
0 \text { to } 2 \cdot 0 \\
0 \text { to } 2 \cdot 0\end{array}$ & $\begin{array}{l}0.53 \\
0.50 \\
0.31 \\
0.96 \\
1.10 \\
1.16 \\
0.97 \\
0.80 \\
0.58 \\
0.98 \\
1.00 \\
0.85 \\
0.58 \\
0.75 \\
0.94 \\
0.91 \\
1.24 \\
0.81 \\
0.72 \\
0.78 \\
0.69\end{array}$ & $\begin{array}{r}0 \\
0 \\
0 \\
4 \\
2 \\
3 \\
8 \\
6 \\
14 \\
9 \\
9 \\
3 \\
6 \\
3 \\
6 \\
3 \\
4 \\
5 \\
10 \\
5 \\
5\end{array}$ & $\begin{array}{l}2 \\
2 \\
1 \\
4 \\
1 \\
2 \\
3 \\
1 \\
0 \\
1 \\
2 \\
1 \\
2 \\
0 \\
1 \\
2 \\
2 \\
2 \\
2 \\
3 \\
1\end{array}$ \\
\hline
\end{tabular}

* ' 2 years' includes all children between $1 \frac{1}{2}$ and $2 \frac{1}{2}$ years, ' 3 years' all those between $2 \frac{1}{2}$ and $3 \frac{1}{2}$ years, etc. 
the mid-clavicular line of more than $3.5 \mathrm{~cm}$. in the newborn would in my experience indicate hepatic enlargement. Zamkin's measurements for older children were $3.5 \mathrm{~cm}$. or less in $79 \%$ of $5-9$-year-old children and $84 \%$ in 10-12-year-old children. These measurements are more in accordance with those of the present series.

The marked retraction of the liver edge between birth and the second year described by Cruchet and Sérégé and repeated by other authors was based on few observations and does not conform with the findings in the present study.

Whilst the use of the fingerbreadth as a measure of projection is a reasonable approximation for a single observer for most clinical purposes, I have found that the lateral diameter of the terminal joint of the index finger may vary from $1.3 \mathrm{~cm}$. in a petite house physician to $2.0 \mathrm{~cm}$. in two robust members of the surgical staff.

That the spleen was palpated in $11.1 \%$ of this series may be considered surprising, but it coincides with my impressions over a number of years. The incidence in the $10 \frac{1}{2}$ to $16 \frac{1}{2}$ year group was, however, higher than anticipated, and has been commented upon. More success in finding the splenic edge in infants will be achieved if its frequently axillary situation is remembered.

\section{Summary}

In 317 apparently healthy infants and children, the projection of the liver edge below the costal margin, the topography of the palpable liver surface and the palpability of the spleen were studied.

When measured in the end-expiratory position, the mean projection of the liver edge below the costal margin in the right mid-clavicular line was slightly less than $2 \mathrm{~cm}$. in the newborn infant, $1.6 \mathrm{~cm}$. in the premature infant, $1.6 \mathrm{~cm}$. during the remainder of the first year, $1 \mathrm{~cm}$. from $1 \frac{1}{2}$ to $10 \frac{1}{2}$ years and $0.85 \mathrm{~cm}$. from $10 \frac{1}{2}$ to $16 \frac{1}{2}$ years.

It was possible to palpate the spleen in $11.1 \%$ of all these subjects, in $13.5 \%$ of newborn babies, in $12.7 \%$ during the remainder of the first year and in $7 \cdot 2 \%$ of those from $1 \frac{1}{2}$ to $10 \frac{1}{2}$ years.

Suggestions for standardizing the procedure for simple clinical measurements of the projection of the liver are made.

I wish to thank Dr. Alex Russell, O.B.E., for his most helpful criticism of this paper; I believe that it was he who first drew my attention to the ease with which the liver can be palpated from the patient's left side; also Prof. M. J. Newell for his help with the statistics.

I wish to thank the following for their kindness in allowing me to examine children under their care: The Master and Dr. W. Kidney, Coombe Maternity Hospital, Dublin; Dr. S. MacLaverty, Regional Hospital, Galway; the Bon Secours Sisters, the Sisters of Mercy, the Sisters of Charity of St. Vincent de Paul and the Irish Christian Brothers.

\section{REFERENCES}

Abt, I. A. (ed.) (1923). Pediatrics. Philadelphia. Brennemann, J. Practice of Pediatrics, Vol. 3, p. 4. Hagerstown, Maryland.

Cruchet, R. and Sérégé, H. (1908). Gaz. hebd. Sci. méd. Bordeaux, $29,158$.

Gaisford, W. and Lightwood, R. (1953). Pediatrics for the Practitioner. London.

Nelson, W. E. (1954). Textbook of Pediatrics, 6th ed. Philadelphia. Zamkin, H. O. (1926). Arch. Pediatrics, 43, 169. 